\title{
Intervenção escolar na educação alimentar infantil quanto aos micronutrientes
}

\author{
Denise da Silva PINHEIRO ${ }^{1}$ \\ Carla CRISTINA ${ }^{2}$ \\ Bruna Alícia Rafael de PAIVA ${ }^{3}$ \\ Rúbia Santos CORREA ${ }^{3}$ \\ Rosália Santos Amorim JESUÍNO ${ }^{4}$
}

\begin{abstract}
RESUMO: As vitaminas e os minerais são substâncias indispensáveis ao funcionamento adequado do organismo. A maioria das crianças que vivem em áreas periféricas dos aglomerados urbanos recebe uma alimentação com baixo valor nutricional, causando problemas de saúde, além de baixa rentabilidade escolar. A carência de micronutrientes na alimentação destas crianças não é devida exclusivamente a um fator econômico, mas também a uma desinformação quanto às fontes nutritivas e a forma como estas podem ser mais bem utilizadas. Este trabalho foi desenvolvido junto à comunidade escolar do colégio estadual Waldemar Mundim (Goiânia, Goiás) com o objetivo de promover a socialização do conhecimento sobre a importância dos micronutrientes para a saúde, com enfoque em alimentos-fonte de baixo custo. A aplicação de um questionário preliminar permitiu diagnosticar uma baixa frequência no consumo regular de verduras, leite e carne pelos alunos, além de baixo nível de conhecimento sobre os micronutrientes. Foram desenvolvidas aulas participativas sobre esta temática, com uso de facilitadores de aprendizagem. Como atividades práticas foram produzidas mudas de frutíferas e verduras, as quais foram distribuídas aos alunos e também plantadas na escola. A análise dos dados obtidos ao final da ação permitiu concluir que houve mudanças significativas tanto no nível de informação, quanto nos hábitos alimentares dos alunos. Espera-se que este trabalho possa trazer melhorias na qualidade de vida destes alunos.
\end{abstract}

PALAVRAS-CHAVE: vitaminas; minerais; educação alimentar infantil; comunidade escolar; alimentos-fonte de baixo custo.

ABSTRACT: Vitamins and minerals are essential substances for proper functioning of the body. Most children living in outskirts of urban areas receive a supply of low nutritional value, causing health problems, and low profitability school. The lack of micronutrients in the diet of these children is not solely due to an economic factor, but also a lack of information about the sources of nutrition and how these can best be used. This work was developed with the community school's state school Waldemar Mundim (Goiânia, Goiás) in order to promote the socialization of knowledge about the importance of micronutrients for health, focusing on food sources of low cost. The application of a preliminary questionnaire enabled us to diagnose a low frequency in the regular consumption of vegetables, milk and meat by the students, and low level of knowledge about micronutrients. Participatory classes have been developed on this theme, using facilitators of learning. Like practical activities have been produced seedlings of fruit and vegetables, which were distributed to students and also planted in the school. Analysis of data obtained at the end of the action allowed concluding that there were significant changes in both the level of information, as in eating habits of students. It is hoped that this work can bring improvements in life quality of these students.

KEYWORDS: vitamins; minerals; child nutrition education; school community; food sources of low cost.

${ }^{1}$ Graduada em Biomedicina pela Universidade Federal de Goiás (UFG), Biomédica do Instituto de Ciências Biológicas (ICB) da UFG. E-mail: facasealuz@ hotmail.com

${ }^{2}$ Graduanda em Nutrição pela Universidade Federal de Goiás (UFG).

${ }^{3}$ Graduanda em Agronomia pela Universidade Federal de Goiás (UFG).

${ }^{4}$ Doutora em Biologia Molecular pela Universidade de Brasília (UNB), mestre em Biologia pela Universidade Federal de Goiás (UFG), graduada em Ciências Biomédicas pela Pontifícia Universidade Católica de Goiás (PUC-GO). Departamento de Bioquímica e Biologia Molecular (DBBM) do Instituto de Ciências Biológicas (ICB) da UFG. E-mail: rosaliajesuíno@gmail.com. 


\section{INTRODUÇÃO}

A deficiência de micronutrientes (vitaminas e minerais) é um problema de grande abrangência na sociedade brasileira e vem adquirindo importância, nos últimos anos, dentro do contexto da saúde pública, quando comparada à deficiência de macronutrientes (proteínas, carboidratos e gorduras) (FERRAZ et al., 2005).

Entre as doenças carenciais por falta de micronutrientes em crianças, a anemia ferropriva e a hipovitaminose A figuram como as deficiências mais enfatizadas tanto nacionalmente quanto internacionalmente (DE ALMEIDA et al., 2004; FERRAZ et al., 2005; RAMALHO et al., 2002).

A maior proporção do acometimento por essas deficiências ocorre de forma subclínica, caracterizando a denominada "fome oculta", o que pode implicar em alterações comportamentais e cognitivas e prejuízos no crescimento das crianças (FERRAZ et al., 2000; LOZOFF et al., 2000; RAMALHO et al., 2002).

Embora as consequências provocadas por estas desordens carenciais e sua incidência sejam maiores em lactentes e préescolares (FERRAZ et al., 2000; HADLER et al., 2002; DE ALMEIDA et al., 2004; FERRAZ et al., 2004), os problemas advindos dessas deficiências, principalmente no que se refere a perdas no desenvolvimento cognitivo, se estendem a escolares e adolescentes (LOZOFF et al., 2000;

HALTERMAN et al., 2001).

Sabe-se que um elevado número de crianças que residem em áreas periféricas dos aglomerados urbanos ou em regiões de vulnerabilidade social recebe alimentação com reduzido valor nutricional acarretando baixa rentabilidade escolar e retardo no desenvolvimento (SOARES et al., 2000; LUCERO et al., 2010).

Com exceção das situações de extrema pobreza, a renda e a escolaridade parecem não serem os maiores fatores relacionados às doenças carenciais, reforçando a tese de que a ingestão inadequada de alimentos seja o seu principal fator etiológico, em que pesam mais questões culturais e hábitos alimentares do que fatores econômicos (RAMALHO, SAUNDERS, 2000).

Todos esses fatos apontam para a necessidade do aumento do consumo de alimentos ricos em micronutrientes como sendo a principal estratégia, a longo prazo, no combate às doenças carenciais. É unânime a idéia de que essa transformação depende de uma profunda e ampla reeducação alimentar (RAMALHO, SAUNDERS, 2000), em que, as crianças figuram como um importante ponto de convergência para o empreendimento eficaz dessas mudanças. Neste sentido este trabalho teve como objetivo principal levar informações sobre micronutrientes a alunos de uma escola 
municipal pública situada em um bairro de periferia na cidade de Goiânia.

\section{MATERIAL E MÉTODOS}

\section{Questionários}

Foram desenvolvidos questionários a fim de verificar o nível de informação dos alunos sobre o tema e avaliar seus hábitos alimentares. As questões foram desenvolvidas tendo em conta os princípios da clareza, coerência, neutralidade e adequação ao público-alvo. Os questionários eram compostos de questões de resposta fechada e foram aplicados a todos os alunos do Colégio Estadual Waldemar Mundim envolvidos no projeto $\left(3^{\circ}\right.$ ao $6^{\circ}$ período) com leitura prévia e explicação de cada questão à toda turma (TRICHES, GIUGLIANI, 2005).

Nas questões sobre hábitos alimentares, baseado em trabalho de Triches e Giugliani (2005), havia as seguintes opções de resposta: "consumo sempre - 3 vezes ou mais por semana" (considerado como consumo regular do alimento); "consumo de vez em quando - de 1 a 2 vezes por semana" (consumo infrequente); “consumo pouco menos que 1 vez por semana" (consumo ocasional).

\section{Construção de facilitadores de aprendizagem}

Os dados obtidos com a aplicação dos questionários foram importantes para o desenvolvimento de pôsteres, aulas expositivas em Power Point e atividades práticas sobre a importância, fontes e consequências da carência de micronutrientes. Durante as aulas foi dado maior enfoque aos alimentos do cerrado e/ou os mais acessíveis em nossa região.

\section{Atividades junto à escola}

Após a equipe de trabalho confeccionar os facilitadores de aprendizagem, os mesmos eram utilizados nas palestras. Foram realizadas visitas semanais à escola de forma atingir os alunos ausentes em palestras anteriores. As palestras eram ministradas em cada turma separadamente, contando com a participação dos educadores da escola, de forma a se obter maior adesão e domínio sobre os alunos, além de proporcionar um maior envolvimento destes profissionais com as atividades desenvolvidas. Todos os materiais produzidos foram repassados à escola.

\section{Análise Estatística}

O mesmo questionário utilizado no início do trabalho foi aplicado novamente ao final da ação desenvolvida para avaliar a efetividade da mesma, empregando-se análise estatística pelo teste do qui-quadrado $\left(\mathrm{X}^{2}\right)$ sobre o número de respostas corretas ou esperadas, antes e após a realização do trabalho.

\section{RESULTADOS E DISCUSSÃO}

A aplicação de um questionário preliminar aos 100 alunos do Colégio Estadual Waldemar Mundim situado no Conjunto Itatiaia I da cidade de Goiânia, do 
$3^{\circ}$ ao $6^{\circ}$ período, com idades entre 8 e 13 anos, permitiu aferir o nível de conhecimento dos mesmos sobre o tema, bem como avaliar seus hábitos alimentares.

Foi verificado que, entre os alunos envolvidos no projeto, $62 \%$ não tinham o hábito de comer verduras regularmente (3 vezes ou mais por semana), fazendo-o apenas de forma infrequente ( 1 a 2 vezes por semana), tendo sido observada situação diametralmente oposta em relação ao hábito de comer frutas, ou seja, $62 \%$ disseram comer frutas regularmente; enquanto que, apenas $56 \%$ tinham o hábito de comer carne e beber leite regularmente. Esses resultados revelaram uma situação preocupante no que se refere à educação alimentar das crianças.

Quanto ao nível de informação sobre os micronutrientes, observou-se que os alunos em sua grande maioria expressaram ter conhecimento sobre a existência das vitaminas $(96 \%)$ e dos minerais $(82 \%)$, tendo sido apontada a mídia televisiva $(68 \%)$ como a principal fonte de informação sobre o tema (Figura 1), enquanto à escola foi creditado apenas $23 \%$ de importância. No entanto, poucos sabiam sobre a relação dos micronutrientes com a alimentação saudável (32\%), ao responder que esta deve conter muitos destes elementos (Figura 2). Uma maioria expressiva dos alunos (66\%) demonstrou não saber que a fonte natural das vitaminas e minerais encontra-se nos alimentos (Figura 3), e que a falta destes é maléfica podendo provocar doenças (73\%) (Figura 4). Apenas uma minoria (19\%) tinha ciência de que o excesso de micronutrientes também pode ser prejudicial (Figura 5). Este fato pode ser explicado pela presença constante da temática das vitaminas e minerais na mídia e pela publicidade de produtos vitamínicos e de reposição mineral, que tendem a enfatizar o caráter benéfico do uso destas substâncias e estimular o seu consumo, marginalizando os possíveis riscos de seu uso indiscriminado (DOS SANTOS, BARROS FILHO, 2002).

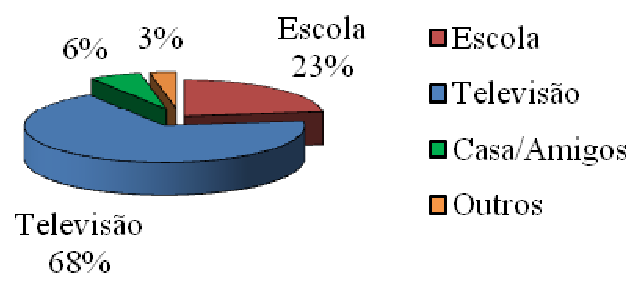

Figura 1 - Fonte de informação sobre micronutrientes de acordo com repostas dos alunos do Colégio Estadual Waldemar Mundim.

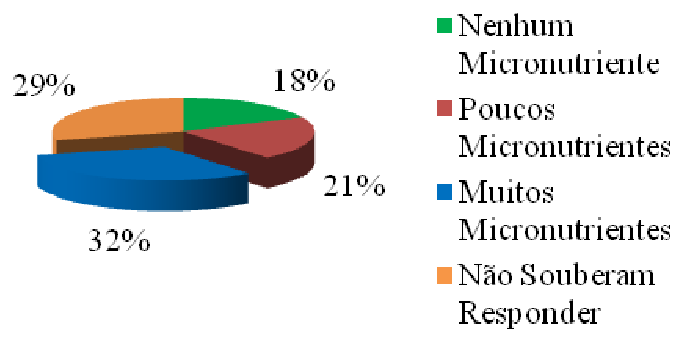

Figura 2 - Relação alimentação saudável x micronutrientes de acordo com alunos do Colégio Estadual Waldemar Mundim ao responder o que uma alimentação saudável deve conter. 


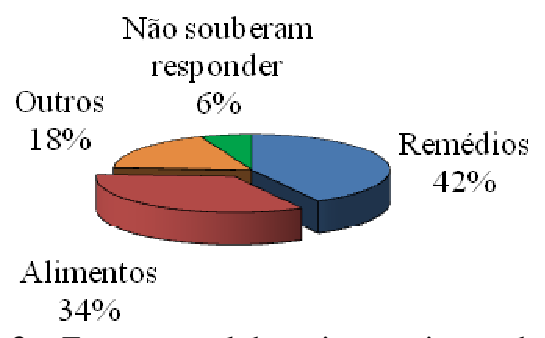

Figura 3 - Fonte natural dos micronutrientes de acordo com repostas dos alunos do Colégio Estadual Waldemar Mundim.

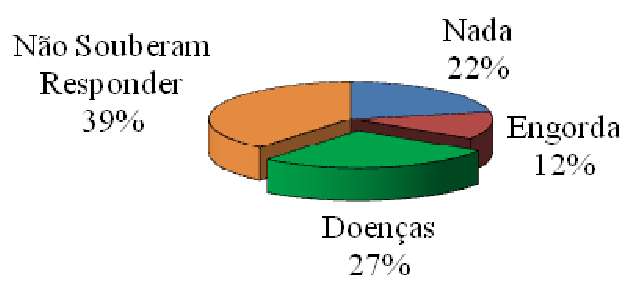

Figura 4 - Consequências da carência de micronutrientes ao organismo de acordo com repostas dos alunos do Colégio Estadual Waldemar Mundim.

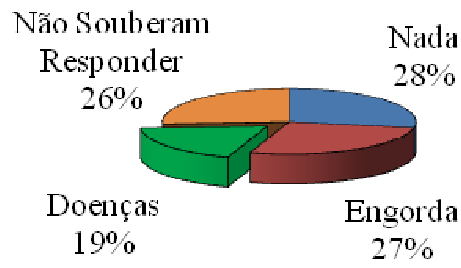

Figura 5 - Consequências do excesso de micronutrientes ao organismo de acordo com repostas dos alunos do Colégio Estadual Waldemar Mundim.

Diante da situação diagnosticada foram confeccionados facilitadores de aprendizagem, entre os quais se destacam: aulas expositivas em Power Point sobre importância, fontes e consequências da carência de micronutrientes, com ênfase sobre anemia e hipovitaminose A (Figura 6 - A); pôsteres apresentando informações sobre vitaminas e minerais de forma didática e ilustrada, dando destaque aos frutos do cerrado (Figura 6 - B); exercícios de colorir para a fixação do aprendizado após a aula expositiva, enfatizando a associação entre os micronutrientes e suas respectivas fontes alimentares (Figura 6 - C); e, como atividade prática, foi realizada uma experiência sobre a atividade das vitaminas (demonstração de que a vitamina $\mathrm{C}$ presente no limão retarda a oxidação da maçã pela água oxigenada) (Figura 6 - D). Também foi realizado o plantio de mudas de frutíferas (mamão e maracujá) e verduras (pimentão e cenoura) na escola. Estas mudas foram distribuídas aos alunos para serem plantadas em suas casas e na escola.
A)

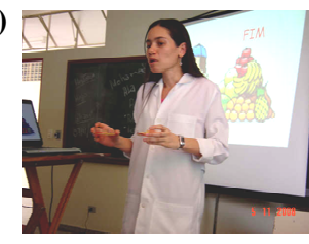

C)

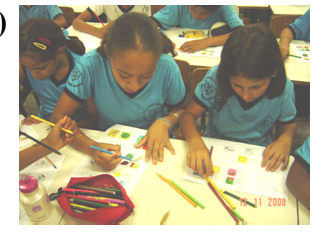

\section{B)}

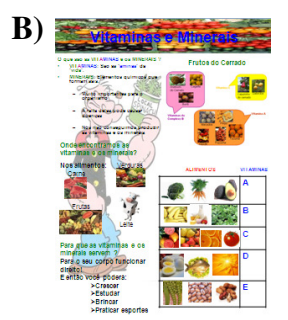

D)

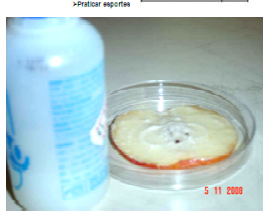

Figura 6 - Facilitadores de aprendizagem desenvolvidos: A) Aula expositiva em Power Point; B) Pôster; C) Atividades para Colorir; D) Experiência prática.

Fonte: própria autora.

Após a realização das atividades propostas, foram obtidos índices de acerto variando entre 67 e $92 \%$ para o mesmo questionário aplicado anteriormente. Considerando os principais aspectos avaliados, estes dados permitem aferir uma melhora significativa tanto na compreensão dos alunos acerca da temática desenvolvida 
(Figura 7), quanto no que se refere aos seus hábitos alimentares (Figura 8), após a aplicação de análise estatística pelo teste do $\mathrm{X}^{2}$. Isso significa que o aumento do nível informacional provocou a modificação do comportamento alimentar dos alunos.

Com respeito aos hábitos alimentares, foi observada uma interessante e inesperada associação entre o consumo de carne e o de leite pelos alunos (Figura 8), uma vez que, o mesmo número de alunos que consumia leite regularmente também indicou o consumo regular de carne, tanto antes quanto após a realização da ação.

Deve-se destacar também o importante incremento no consumo regular de verduras, conforme pode ser verificado na figura 8 , o que se configurou como um dos focos do projeto, tendo em vista a verificação de que as verduras eram os alimentos de mais baixo consumo pelas crianças.

A comparação dos dados obtidos antes e após o desenvolvimento do projeto está de acordo com o trabalho de Triches e Giugliani (2005). Estes autores ao investigarem sobre os hábitos alimentares das crianças também observaram uma relação entre hábitos alimentares mais saudáveis e maior conhecimento sobre nutrição. Além disso, estes autores, apesar de utilizarem metodologia de análise diferente da empregada neste trabalho, também encontraram baixos índices de acerto por parte das crianças na maioria das questões sobre alimentos, o que os levou a concluir que estas crianças tinham baixo conhecimento sobre nutrição.

Esses resultados demonstram que a transmissão do conhecimento é uma ferramenta capaz de promover alterações salutares na vida dos indivíduos, inclusive crianças, reforçando a importância da realização de projetos e campanhas educativas com enfoque social, além de apontar que o nível econômico não é o fator mais importante na questão nutricional (RAMALHO, SAUNDERS, 2000).

Este trabalho de extensão foi desenvolvido utilizando como ferramenta de modificação social a transmissão de conhecimentos, desta forma, teve a limitação de não ter realizado medidas de indicadores do estado nutricional das crianças, como o índice de massa corporal e a dosagem de micronutrientes no sangue. Entretanto, acredita-se que a abordagem desenvolvida neste projeto possa contribuir no combate ou na prevenção das deficiências nutricionais a longo prazo. Neste sentido, vários trabalhos têm sugerido a educação nutricional na escola como uma importante prática voltada à saúde social que deveria, inclusive, fazer parte do currículo escolar obrigatório (PÉREZRODRIGO, ARANCETA, 2003; BIZZO, LEDER, 2005). 


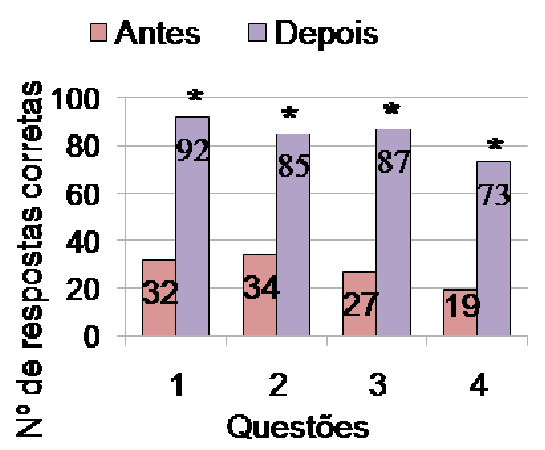

Fígura 7 - Nível de informação sobre o tema: comparação entre as repostas obtidas pela aplicação do mesmo questionário antes e após o desenvolvimento da ação. Análise estatística pelo teste do $\mathrm{X}^{2}$, com nível de significância para $\mathrm{p}<0,001(*)$. Questões:

1. Relação alimentação saudável x micronutrientes;

2. Fonte natural dos micronutrientes;

3. Consequências da carência de micronutrientes;

4. Consequências do excesso de micronutrientes.

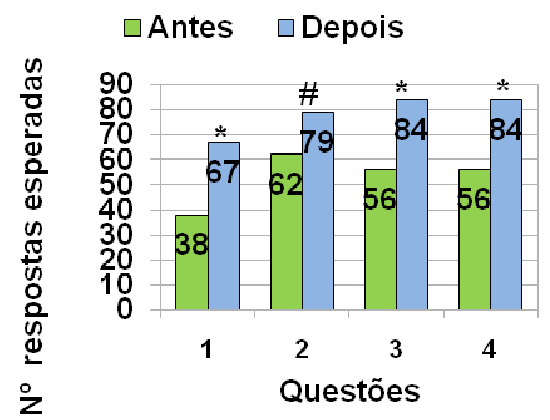

Fígura 8 - Hábitos alimentares dos alunos: comparação entre as repostas obtidas pela aplicação do mesmo questionário antes e após o desenvolvimento da ação. Análise estatística pelo teste do X2, com nível de significância para $\mathrm{p}<0,001(*)$ e para $\mathrm{p}<0,05(\#)$. Questões:

1. Consumo de verduras regularmente;

2. Consumo de frutos regularmente;

3. Consumo de carne regularmente;

5. Consumo de leite regularmente.

\section{CONCLUSÕES}

Os dados obtidos reforçam a importância da realização de trabalhos sociais com enfoque sobre alimentação saudável a baixo custo como preconizado pela política nacional para segurança alimentar definida pela I Conferência Nacional de Segurança Alimentar (BRASIL, 1994). Estes resultados reforçam a necessidade de uma atuação firme da escola na questão da educação alimentar, tendo em vista o fato de que as crianças passam boa parte de seu tempo neste local e muitas vezes não dispõem de uma referência de bons hábitos alimentares em casa.

A aplicação dos facilitadores de aprendizagem que foram desenvolvidos possibilitou aos alunos melhorias na alimentação, noções sobre a importância de uma alimentação saudável, rica em vitaminas e em minerais, causas e consequências da carência nutricional, além de noções sobre educação ambiental. Espera-se que todas estas ações incentivem o consumo de vegetais pelos alunos, assim como, despertem nestes a consciência ambiental da relação entre o ser humano e a natureza.

A disponibilização dos materiais produzidos à escola e o envolvimento dos educadores nas atividades desenvolvidas viabilizarão a continuidade do trabalho por estes profissionais, propiciando o ganho de maior efetividade na implantação de uma proposta curricular sobre o tema da educação nutricional (KEALEY et al., 2000; PÉREZRODRIGO, ARANCETA, 2003).

Como perspectivas para novos estudos, pode-se assinalar a análise da relação entre a melhoria dos hábitos alimentares dos alunos e o rendimento escolar, o que poderia ser verificado em trabalhos de maior duração. 


\section{AGRADECIMENTOS}

Agradecemos à Pro Reitoria de Extensão e Cultura (PROEC) da Universidade Federal de Goiás pela seleção do projeto no

\section{REFERÊNCIAS}

BIZZO, M. L. G.; LEDER, L. Educação nutricional nos parâmetros curriculares nacionais para o ensino fundamental. Rev. Nutr., Campinas, v.18, n.5, p.661-667, 2005. www.scielo.br/pdf/rn/v18n5/a09v18n5.pdf

BRASIL. Conselho Nacional de Segurança Alimentar (CONSEA). Diretrizes para uma política nacional de segurança alimentar. Brasília, DF, 1994.

DE ALMEIDA, C.A.N. et al. Fatores associados a anemia por deficiência de ferro em crianças pré-escolares brasileiras. $\mathbf{J}$

Pediatr., Rio de Janeiro, v. 80, n. 3, p. 22934, 2004.

http://www.scielo.br/pdf/jped/v80n3/v80n3a1 2.pdf

DOS SANTOS, K. M. O.; BARROS FILHO, A. A. Crenças sobre as vitaminas e consumo de produtos vitamínicos entre universitários de São Paulo. ALAN, Caracas (Venezuela), v.52, n.3, 2002.

http://www.scielo.org.ve/scielo.php?script=sci arttext\&pid=S0004$\underline{06222002000300003 \& \operatorname{lng}=e s \& n r m=i s o \& t \operatorname{lng}}$ $=\mathrm{pt}$

FERRAZ, I.S. et al. Detection of vitamin A deficiency in Brazilian preschool children using the serum 30-day dose-response test. Eur J Clin Nutr., v.58, p.1372-7, 2004. http://www.nature.com/ejcn/journal/v58/n10/ pdf/1601978a.pdf

FERRAZ, I.S. et al. Prevalência da carência de ferro e sua associação com a deficiência de vitamina A em pré-escolares. J Pediatr., Rio programa de bolsas PROBEC, à Fundação de Apoio à Pesquisa (FUNAPE) pelo apoio concedido, e ao Colégio Estadual Waldemar Mundim pela abertura e receptividade ao desenvolvimento de novas propostas.

de Janeiro, v. 81, n.2, p.169-74, 2005. http://www.scielo.br/pdf/jped/v81n2/v81n02a 14.pdf

FERRAZ, I.S.; DANELUZZI, J. C.; VANNUCCHI, H. Vitamin A deficiency in children aged 6 to 24 months in São Paulo state, Brazil. Nut Res., São Paulo, v.20, n. 6, p. 757-68, 2000.

http://www.sciencedirect.com/science/article/ pii/S0271531700001779

HADLER, M. C. C. M.; JULIANO, Y., SIGULEM, D. M. Anemia do lactente: etiologia e prevalência. J Pediatr., Rio de Janeiro, v.78, n. 4, p.321-6, 2002. http://www.scielo.br/pdf/\%0D/jped/v78n4/v7 8n4a12.pdf

KEALEY, K. A. Teacher training as a behavior change process: principles and results from a longitudinal study. Health Educ. Behav, v. 27, p.64-81, 2000. http://heb.sagepub.com/content/27/1/64.full.p df+html

LOZOFF, B. et al. Poorer behavioral and developmental outcome more 10 years after treatment for iron deficiency in infancy.

Pediatrics, v. 105, n. 4, 2000. http://pediatrics.aappublications.org/content/1 05/4/e51.full.pdf+html

LUCERO, L. M. et al. Acompanhamento nutricional de crianças de baixa renda que se beneficiam do programa nacional de alimentação escolar (PNAE). Revista da AMRIGS, Porto Alegre, v. 54, n. 2, p.156161, 2010. http://www.amrigs.org.br/revista/54-02/08509_acompanhamento.pdf 
PÉREZ-RODRIGO, C.; ARANCETA, J.

Nutrition education in schools: experiences and challenges. European Journal of Clinical Nutrition, v.57, Suppl 1, S82-S85, 2003.

http://www.nature.com/ejcn/journal/v57/n1 s/p df/1601824a.pdf

RAMALHO, R. A.; FLORES, H.;

SAUNDERS, C. Hipovitaminose A no Brasil: um problema de saúde pública. Pan Am J Public Health, v. 12, n. 2, p. 117-123, 2002. http://www.scielosp.org/pdf/rpsp/v12n2/1161 $\underline{3 . p d f}$

SOARES, T. N. et al. Padrão alimentar de lactentes residentes em áreas periféricas de Fortaleza. Rev Nutr., Campinas, v. 13, n. 3, p. 167-176, 2000.

http://www.scielo.br/pdf/rn/v13n3/7903.pdf

TRICHES, R. M.; GIUGLIANI, E. R. J.

Obesidade, práticas alimentares e conhecimentos de nutrição em escolares. Rev Saúde Pública, v.39, n. 4, p.541-7, 2005.

http://www.scielo.br/pdf/rsp/v39n4/25523.pdf 